\title{
Distribuição e Atuação dos Psicólogos na Rede de Unidades Públicas de Saúde no Brasil
}

Distribution and action of psychologists at the Brazilian public health system

Resumo:Realizou-se uma análise dos dados cadastrais registrados no Sistema de Informações Ambulatoriais do Sistema Único de Saúde (SIA-SUS), do Ministério da Saúde, construindo-se um panorama da distribuição dos profissionais de Psicologia e dos serviços que estão prestando. Os psicólogos perfazem 1,0\% dos profissionais cadastrados no SIA-SUS. Como ocorre para outras profissões, a Região Norte encontra-se em situação de maior desvantagem em relação à disponibilidade desses profissionais. Observou-se que a distribuição de psicólogos por Estado não se relaciona diretamente com o número de habitantes ou com a dimensão da rede instalada. Os dados possibilitaram discutir a relação entre a inserção profissional, suas práticas e os modelos de atenção, com vistas à adoção de políticas de saúde orientadoras dos serviços de Psicologia nas unidades públicas de saúde.

Palavras-Chave: Psicologia, saúde pública, saúde mental, profissionais de Psicologia.

Abstract: By the analysis of data obtained in the Brazilian Health Information System of the Secretary of Health was carried out allowing an overview of the distribution of psychologists in the Unified Health Brazilian System (SUS) and of the services they offer. Professionals of the psychological field comprised $1,0 \%$ of the total registered, and just as with other professions the Northern Region is in greater disadvantage. In addition, the distribution of psychologists per state is not related to the number of habitants or the health unit network. These data make it possible to discuss the adoption of different guiding policies for the action of psychologists in the public health services.

Key Words: Psychology, public health, mental health, psychology professionals.

\section{Anamélia Franco}

Psicóloga, Mestre em Psicologia do Desenvolvimento - UNB, Doutora em Saúde Pública-UFBA

\section{Eduardo Mota}

Professor-adjunto Doutor do Instituto de saúde Coletiva-UFBA

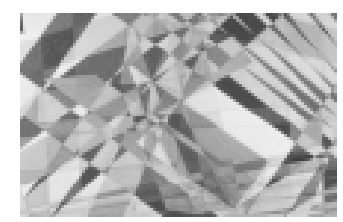

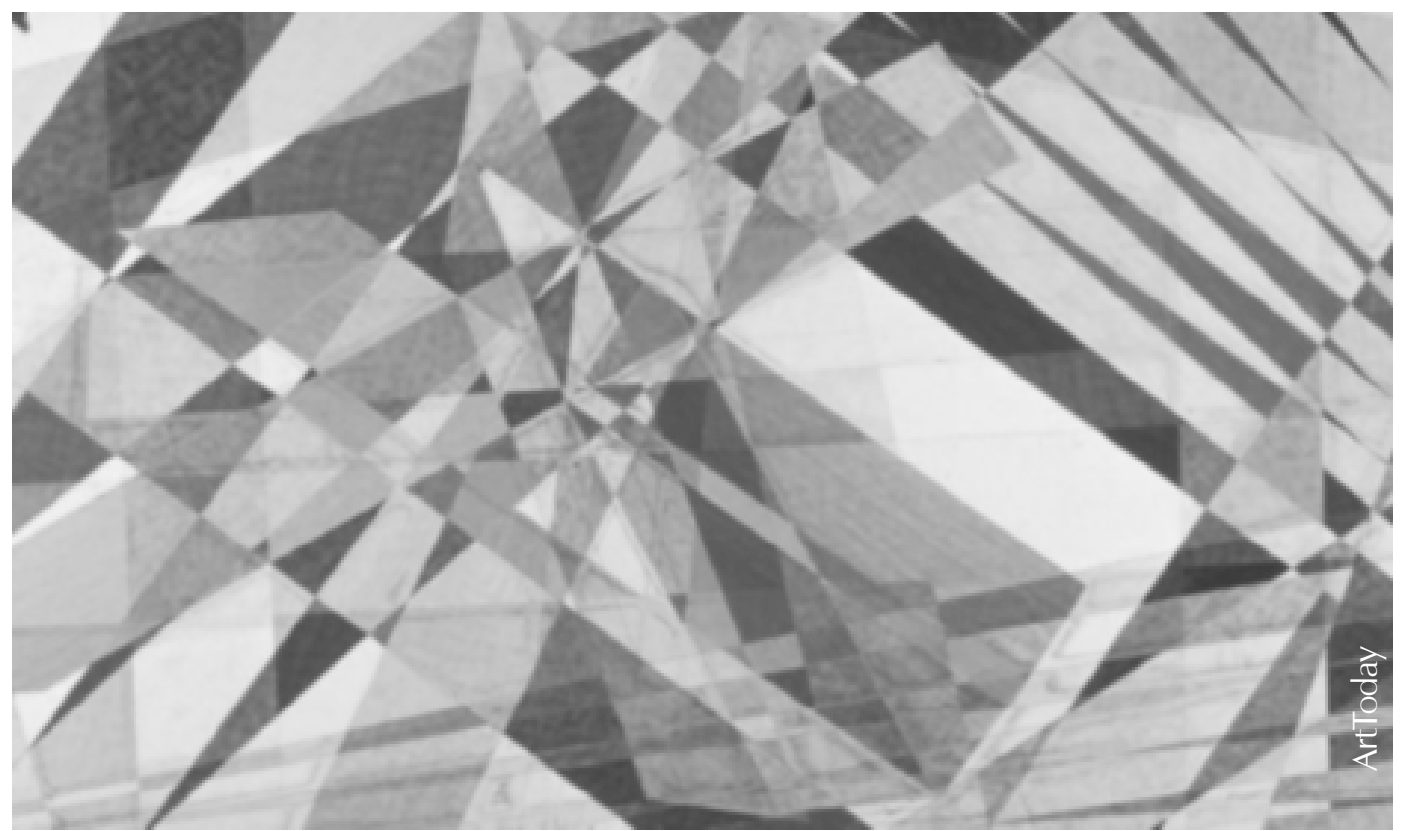

A atuação do psicólogo tem sido objeto de estudos e discussões em diversos fóruns. O Conselho Federal de Psicologia (CFP), desde a publicação da pesquisa Quem é o Psicólogo Brasileiro? (1988), seguindo-se diversas outras publicações, inclusive as mais recentes sobre diretrizes curriculares, tem mantido e apoiado o debate articulando a formação em Psicologia, a atuação do psicólogo e o compromisso social da profissão. Essa reflexão freqüentemente enfatiza que o crescimento e o fortalecimento da atuação do psicólogo se relaciona com a competência para atender às demandas da população brasileira. 
A profissão de psicólogo possibilita ao profissional uma diversificada gama de alternativas de atuação que, em outras profissões, parecem não se apresentar tão explícitas. Bock (1998), ao analisar as representações de si e da profissão, demonstra que esta é fortemente vinculada à atuação clínica, reconhecida como uma prática solitária. Ao afirmarse que a profissão de psicólogo se vincula à atuação clínica, precisa-se distinguir, em nosso contexto, que essa clínica é a clínica de consultório - consultório particular e predominantemente individual, onde se responde às demandas-queixas de indivíduos das classes média e alta. Isso faz com que o profissional busque alternativas de atuação entre as quais estaria a atividade institucional, aproximando-o de seus colegas, da equipe de trabalho e da população. Uma segunda alternativa seria a carreira acadêmica, que oferece convívio com colegas e alunos, e que resulta, tanto quanto para a primeira alternativa, em um padrão de trocas específico.

Apesar de o texto apresentado por Bock datar de 1998, naquele momento já era possível questionar a oferta de empregos, a natureza da vida acadêmica e a estabilidade da atividade clínica. Com o fortalecimento de novos modelos de contratação geradores de novas relações de trabalho e a consolidação das organizaçõ̃es não-governamentais como campo de exercício profissional, entre outras, as concepções de área de atuação e especialização profissional passaram a considerar uma nova realidade.

Esses desafios foram apresentados por Yamamoto (1996). Esse autor, contextualizando e prevendo as mudanças para a Psicologia, constrói um texto questionando os profissionais quanto às imposições e aos desafios decorrentes da globalização. Inicialmente este autor relembra Botomé quando afirma que, em 1979 , apenas $15 \%$ da população tinha acesso aos serviços de psicólogos e ainda questiona se os outros $85 \%$ não necessitavam desse atendimento. Em seguida, apresenta uma discussão com base nos dados resultantes do recadastramento dos psicólogos da 6 região - São Paulo (1995). Esse recadastramento utilizou a denominação da "psicologia da saúde" como uma compreensão mais ampla para a clínica. O autor considerou que a mudança para a denominação de psicologia da saúde possibilitaria uma ampliação do entendimento das possibilidades da Psicologia, proporcionando alternativas à população excluída do atendimento privilegiado oferecido nos consultórios. Aparentemente, a esperança apresentada não se concretizou. Observa-se que $40,8 \%$ do total dos psicólogos da $6^{a}$ região exercem suas atividades em consultório particular. Acrescente-se que Spink (1992) e Silva (1992) ampliaram a atuação do psicólogo em saúde e na saúde pública, respectivamente. Eminentemente, o que as publicações de que está aí colocado por essas autoras e os outros autores que a elas se congregaram nessa publicação é a proposição do trabalho do psicólogo em outros níveis de atenção, além da atenção secundária, na qual se trabalha na remissão de um dano identificado, no caso da Psicologia, a queixa orientadora do atendimento.

Esses elementos apontam que, para a Psicologia, a questão dos modelos de atenção é uma discussão ainda muito incipiente e, quando aparece, está circunscrita ao cuidado aos portadores de sofrimento psíquico. O futuro da profissão está em jogo e uma das cartas principais desse jogo são os modelos de atenção adotados. Atuar na promoção e na proteção à saúde, na prevenção de riscos e agravos e na reabilitação não exclui o contexto do consultório e da atenção clínica, mas indica a pertinência de outros níveis, contextos e modos de atuação. Portanto, o desafio de disponibilizar atendimento psicológico para a população brasileira exige formulações teóricas, estratégias de ação e fundamentos em política e economia da saúde que coexistam de forma integrada e articulada.

A análise apresentada nessa oportunidade pretende contribuir para essa linha de reflexão, proposta há muito pelo CFP como também por Yamamoto (1996), Spink (1992) e Silva (1992). Os resultados podem contribuir para a discussão expressa na preocupação de Botomé, em torno da indisponibilidade de atenção especializada para os $85 \%$ da população que seguramente não têm acesso aos consultórios particulares, um percentual que pode ser ainda maior considerando-se o aprofundamento das desigualdades sociais ocorrido nesses últimos vinte anos. Como elementos orientadores dessa análise, foram elaboradas algumas perguntas: como se distribui regionalmente e como vem se dando a atuação do psicólogo nos serviços de saúde? Essa atuação reproduz o modelo clínico de consultório ou já se vê alguma diversificação das alternativas de atuação? Qual o volume de trabalho desse profissional e como as atividades desenvolvidas são registradas?

Considerações Metodológicas - Os dados do Sistema de Informações Ambulatoriais do Sistema Único de Saúde (SIA-SUS) foram obtidos de disco compacto (CD-ROM) ou via Internet, editados pelo Departamento de Informática do SUS (DATASUS) do Ministério da Saúde. Todas as informações sobre serviços produzidos e de natureza cadastral são geradas pelos prestadores de serviços contratados e conveniados ao SUS e da rede própria de unidades estaduais e municipais de saúde. Foram utilizados dados cadastrais de dezembro de 1998 e dados populacionais obtidos de estimativa do IBGE para o mesmo ano. As tabulações foram feitas com o aplicativo TABWIN do DATASUS. No desenvolvimento do texto, optou-se por uma 
estrutura em que os dados são os principais orientadores da discussão. Sendo assim, conceitos e termos relativos ao processo de implantação do SUS serão apresentados e explicados ao longo da discussão.

Informações e considerações - Na Tabela 1, apresentam-se o número total de profissionais, o número de profissionais de Psicologia e Psiquiatria e a proporção destes sobre o total de profissionais das unidades ambulatoriais do SUS, por Estado e região. Os profissionais especializados da área de saúde mental representaram 1,53\% do total dos profissionais. O número de profissionais de Psicologia foi pouco mais do dobro (14.504) do número de profissionais de Psiquiatria (6.684). Esses números geram um certo otimismo quando se considera que é desejável oferecer serviços orientados por um modelo assistencial baseado nos princípios de prevenção e de promoção da saúde, ao tempo em que se ampliam o campo e as exigências para a atuação do psicólogo.

Importantes diferenças regionais foram observadas na distribuição dos profissionais. Em geral, as menores proporções foram as do Nordeste e Norte, sendo mais baixas para esta última região. Em contraste, proporções mais elevadas dos dois grupos profissionais encontravam-se na Região Sudeste. Esse perfil se superpõe à distribuição dos centros formadores no País.

Tabela 1 - Número total de profissionais, número de profissionais de Psicologia e Psiquiatria e proporção desses sobre o total de profissionais cadastrados nas Unidades Ambulatoriais do SUS, por Estado e região, Brasil, 1998.

Importantes

diferenças regionais foram observadas

na distribuição dos profissionais. Em

geral, as menores proporções foram as do Nordeste e Norte,

sendo mais baixas

para esta última região. Em contraste,

proporções mais elevadas dos dois grupos profissionais encontravam-se na Região Sudeste. Esse perfil se superpõe à distribuição dos centros formadores no País. 
A Região Nordeste é o caso mais excepcional de diferenças no número de profissionais entre Estados de uma mesma região. Alagoas, Paraíba e Pernambuco apresentaram proporções de psicólogos em torno do dobro da média da região, com valores deste indicador equivalentes ao que se verificou no Sudeste. Isso poderia também estar relacionado à disponibilidade de centros formadores. Pernambuco possui, há pelo menos duas décadas, três cursos de graduação em Psicologia. Essa situação não se estende àqueles outros dois Estados, o que pode revelar diferenças na política governamental quanto à inclusão do psicólogo na equipe de saúde.

Confrontou-se a produção média dos profissionais de Psicologia por dez mil habitantes e o número médio desses profissionais por cem mil habitantes (Tabela 2). As regiões Norte e Nordeste foram as que apresentaram valores médios mais baixos de procedimentos e de profissionais. Ao mesmo tempo, pode-se observar grandes diferenças entre os Estados. Tomem-se como exemplos os Estados do Ceará, Piauí e Sergipe. Embora existisse número semelhante de profissionais por 100.000 habitantes, foram realizados no Ceará 100,0 procedimentos, enquanto Piauí e Sergipe registraram, respectivamente, 52,4 e 33,6 procedimentos por 10.000 habitantes. Mais surpreendente ainda foi o que se observou para o Maranhão, que, apesar de registrar 1,4 profissionais por 100.000 habitantes, realizou 119,9 procedimentos por 10.000 habitantes. Nas regióes Sudeste e Sul, encontraram-se os valores mais elevados entre os Estados; entretanto, ocorreram também algumas diferenças importantes na relação entre a disponibilidade de profissionais e procedimentos registrados por habitante. No geral, no Centro Oeste registrou-se menor produção em relação ao número de profissionais, com exceção do Mato Grosso.

Ao longo desta e das próximas análises, se mantêm algumas questões. A atenção à saúde pode ser orientada por várias concepções e estas são denominadas, em geral, de modelos de atenção. Poderiam trazer elementos para a compreensão do modelo de atenção observar como se incorpora o psicólogo no processo saúde-doençacuidado, o quanto os psicólogos trabalham na prevenção ou na reabilitação, se orientam suas atividades a partir da demanda espontânea ou se usam algum tipo de programação e se prestam atendimento individual ou em grupo.

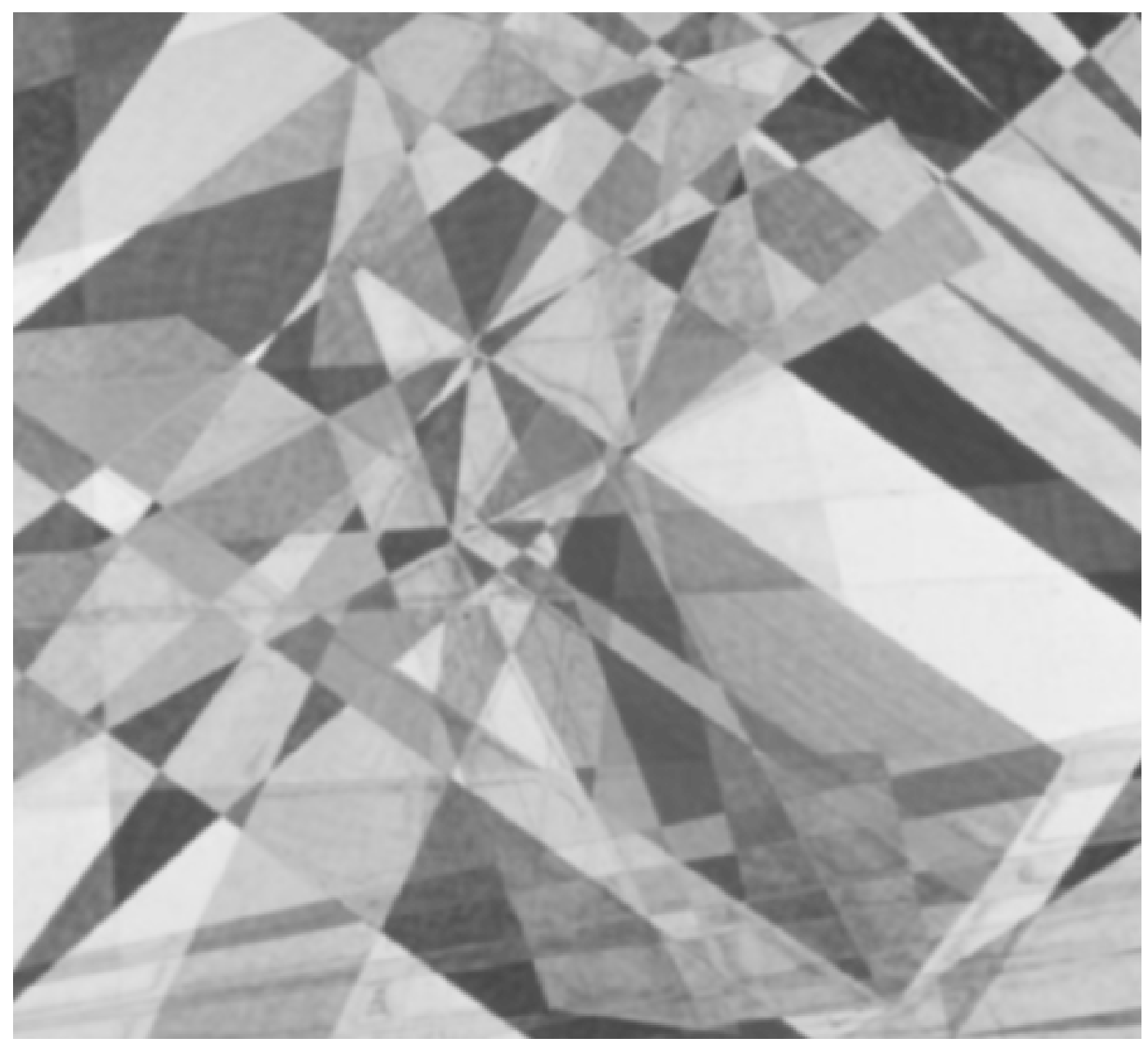

Ao longo desta e das próximas análises, se mantêm algumas questões. A atenção à saúde pode ser orientada por várias concepções e estas são denominadas, em geral, de modelos de atenção. 
Tabela 2 - Número total de procedimentos* / número de procedimentos por 10.000 habitantes realizados por profissionais de Psicologia e número de psicólogos por 100.000 habitantes, cadastrados nas Unidades Ambulatoriais do SUS, por Estado e região, Brasil, 1998.

Voltando às informações, questiona-se: os registros refletem os modelos de atenção adotados pelos respectivos Estados? As discrepâncias entre o número de profissionais e o número de procedimentos seriam indicações válidas para a avaliação da qualidade do registro dos procedimentos? Nesse caso, poder-se-ia inferir que os Estados do Maranhão, Ceará, Bahia e Mato Grosso do Sul seriam exemplos de super-registro e Goiás, Mato Grosso e Espírito Santo seriam exemplos de sub-registro de procedimentos.

O registro do procedimento é um ato tido como burocrático. Entretanto, esse registro é o meio pelo utilizando-se informações que também são

aplicadas nas estimativas de recursos financeiros. Praticamente em todo o setor saúde, há necessidade de aperfeiçoar a qualidade dos dados, principalmente em decorrência de sub-registro, como é o caso das ações em Psicologia. Esse ponto coloca para a categoria a necessidade de repensar suas rotinas mais específicas. O registro das atividades realizadas pelos psicólogos torna-se o documento que atesta sua produtividade e é fonte de avaliação e de produção de conhecimentos. Sabe-se que registros em prontuário são documentos que protegem tanto os usuários quanto os profissionais. Em nome do sigilo, sempre se discute o teor dos registros, e a discussão sobre estes não fere os princípios do sigilo e demonstram a produtividade, diferenciando a natureza do 
serviço prestado e, conseqüentemente, a pertinência desses, nesta análise, do psicólogo na rede SUS.

Analisou-se a distribuição do número médio de procedimentos por profissional por mês (Tabela 2). Destacaram-se os Estados do Maranhão e do Paraná com os valores médios mais elevados. Comparandoos, nota-se que, embora tivessem níveis semelhantes de produtividade, parece haver maior cobertura de serviços especializados no Paraná, conseqüente a um número muito maior de profissionais por habitante.

Como ocorreram casos que revelaram freqüências muito abaixo da média, como no Amapá e em outros quatro Estados que apresentaram menos de 20 procedimentos por profissional/mês, pode-se supor que há efetivamente baixa produtividade ou considerável sub registro das atividades. As duas opções colocam, para a categoria, elementos para reflexões profundas: se produzimos muito pouco, não assumimos responsavelmente o cuidado da saúde que podemos dispensar à população; se não registramos o que fazemos, não podemos mostrar o quanto respondemos às demandas por esses serviços.

Estudando-se a distribuição percentual do número de procedimentos por tipo, realizados por profissionais de Psicologia (Tabela 3), observou-se que, em todas as regiões, entre $69 \%$ e $83 \%$ dos procedimentos ambulatoriais realizados por psicólogos foram registrados genericamente como "consulta ou atendimento" de profissional de nível superior. Isso revela as próprias limitações do registro de atendimentos do PAB - Piso de Atenção Básica (Ministério da Saúde, 1997), que nomeia os atendimentos que não são realizados por médico e pessoal de enfermagem como um conjunto indistinto de consultas. Com efeito, na organização da assistência ambulatorial do SUS, os atendimentos de Psicologia são considerados especializados, razão porque os atendimentos feitos por profissionais de nível superior que não se incluem entre aqueles da atenção básica são registrados sem discriminação mais específica de tipo.

A partir dos dados por tipo de procedimento, podem-se formular algumas questões: quais seriam os procedimentos de atenção psicológica que comporiam a atenção básica? Esses atendimentos registrados como parte do PAB corresponderiam às intervenções em atenção básica, realmente? A permanecer a atuação do psicólogo em atenção básica, como se definiria tal atuação?

Figuraram em segundo lugar em freqüência relativa $(17,7 \%)$ os registros das terapias individuais e em grupo. Esses procedimentos poderiam estar relacionados às atividades do psicólogo em atendimentos aparentemente processuais, o que parece mais pertinente às intervenções psicoterapêuticas. Destaca-se o "psicodiagnóstico", com $3,6 \%$ no geral, notando-se variações entre as regiões, em especial a menor freqüência desse procedimento nas regióes Sul e Norte. É notável, ainda, a participação do psicólogo em atividades educativas e sua integração às atividades dos Programas de Saúde da Família, embora de menor expressão, e o atendimento nos Núcleos e Centros de Atenção Psicossocial, este relativamente maior na Região Nordeste. Esses dados retomam a discussão do perfil de atuação do psicólogo em função do modelo de atenção básica e ambulatorial que se adote, isto é, o maior ou menor equilíbrio de participação entre as atividades diagnóstica e terapêutica e as atividades educativas e de promoção da saúde da família em atendimentos domiciliares.

Tabela 3 - Distribuição percentual do número de procedimentos* realizados por profissionais de Psicologia nas Unidades Ambulatoriais do SUS, por tipo e região, Brasil, 1998.

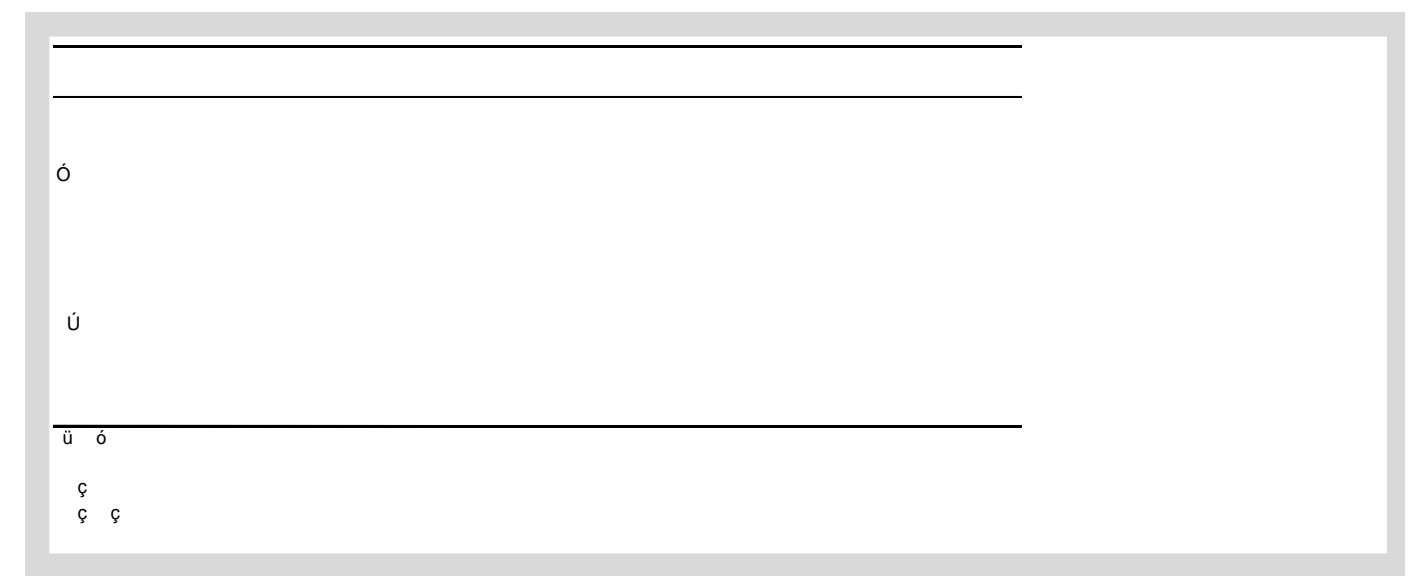


Além das informações sobre as atividades e a produtividade dos psicólogos no SUS, as bases de dados possibilitaram analisar os tipos de unidade onde esses profissionais estavam cadastrados (Tabela 4). O maior número de psicólogos encontrava-se atuando em clínicas especializadas, policlínicas e consultórios (33,3\%) e, em seguida, em centros e postos de saúde (29,4\%). Essa distribuição por local de trabalho no País teve padrão semelhante à da Região Sudeste. Na Região Sul, a proporção de profissionais que atuavam em unidades básicas foi maior (40,5\%), enquanto nas regiões Centro Oeste e Nordeste ocorreu maior proporção de psicólogos em serviços ambulatoriais de unidades hospitalares, com respectivamente 40,0\% e 32,5\%.

Esses dados podem significar que há maior investimento na mudança de modelo assistencial nos Estados da Região Sul, colocando o profissional psicólogo "na ponta" do Sistema - na rede básica. Uma freqüência relativamente maior de profissionais que atuavam em Núcleos de Atenção Psicossocial no Sudeste, Norte e Nordeste em relação às outras regiões aguarda avaliação específica quanto aos resultados e impacto da mudança no modelo assistencial para os portadores de sofrimento psíquico e se isso tem se acompanhado de redução de internações e de leitos hospitalares para a assistência psiquiátrica. Confrontando a forma de registrar os procedimentos (Tabela 3) com a lotação dos profissionais por tipo de unidade (Tabela 4), supõe-se que os psicólogos no Nordeste usam melhor do registro de procedimentos em atenção básica, apesar da organização dos serviços ainda mantê-los principalmente no ambiente hospitalar.

Tabela 4 - Número de profissionais de Psicologia cadastrados no SUS, por grandes tipos de unidades, por região, Brasil 1998.

\section{Confrontando a forma de registrar os procedimentos (Tabela 3) com a lotação dos profissionais por tipo de unidade (Tabela 4), supõe-se que os psicólogos no Nordeste usam melhor do registro de \\ procedimentos em atenção básica \\ apesar da \\ organização dos serviços ainda mantê- los principalmente no ambiente hospitalar.}

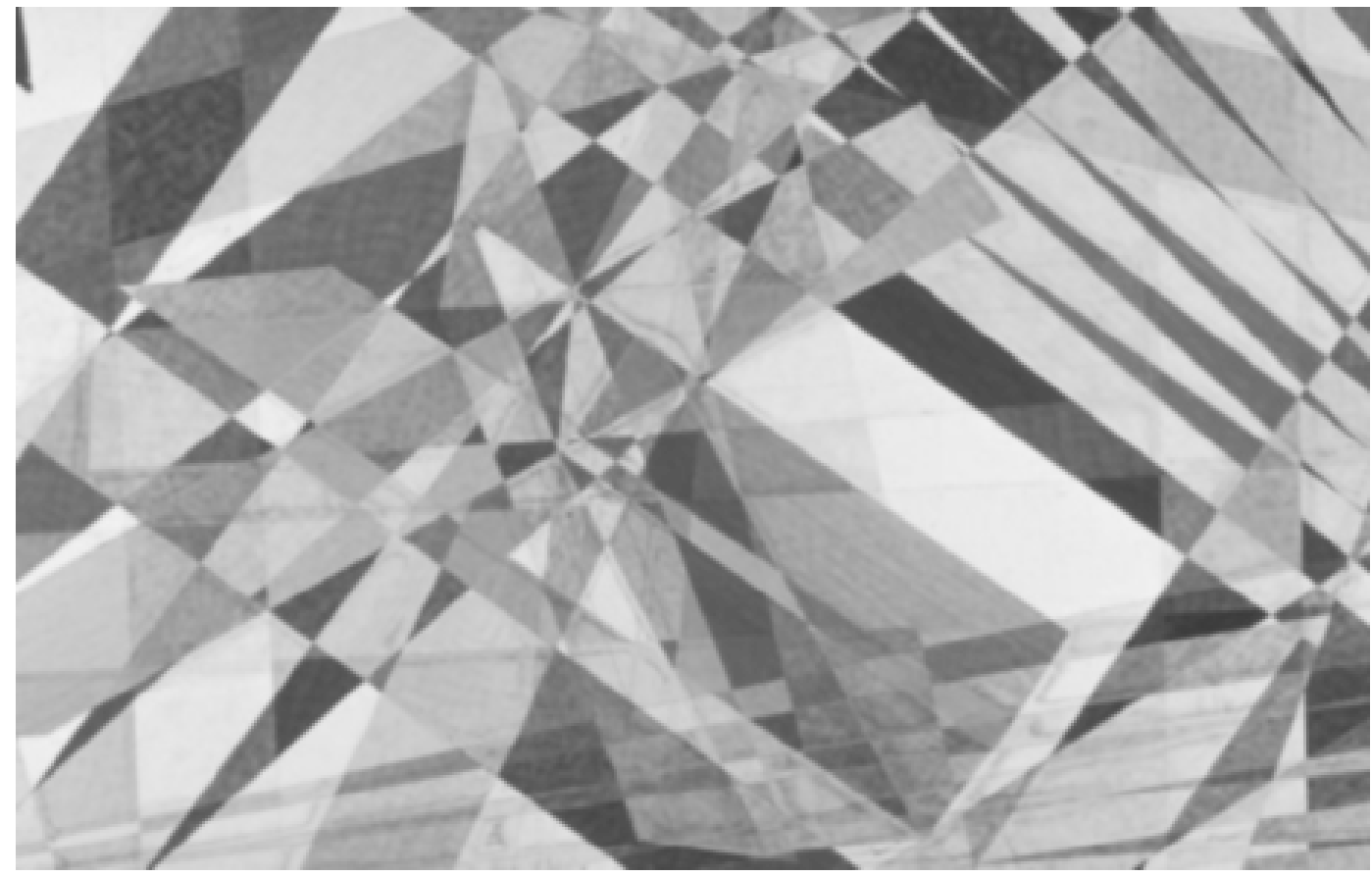




\section{Considerações Finais}

Avalia-se que, apesar do ano de referência das informações ser 1998, não tenham ocorrido mudanças na realidade da atenção psicológica do SUS em período recente que comprometessem a validade dos dados. Considere-se também que alguns resultados dependem da qualidade do cadastro de profissionais do SUS. Entretanto, uma análise comparativa entre a situação atual e o perfil apresentado para o período estudado poderia revelar tendências que subsidiariam adicionalmente a reflexão sobre a inserção dos psicólogos na rede ambulatorial, sua distribuição e atuação e a qualidade dos dados registrados.

A análise das informações pode suscitar várias questões para os psicólogos enquanto categoria, de acordo com seu compromisso com a saúde da população. Não se pode perder de vista que a incorporação de novos profissionais ou a oferta de ações do psicólogo em saúde pública se defronta com uma realidade na qual se observa a flexibilização das profissões e o enxugamento dos quadros do Estado (Yamamoto, 1996).

Sendo assim, poder-se-ia sintetizar algumas dessas questões em torno dos seguintes pontos:

- Não é grande o número de psicólogos cadastrados no SUS por Estado. Para ampliá-lo, torna-se necessário apresentar desde a formação condições para modificar essa realidade. Uma das bases para essa ação seria o princípio constitucional da eqüidade em saúde;

- A inserção de psicólogos nos serviços públicos de saúde deve suscitar uma ampliação e redefinição das suas práticas;

- A qualidade dos dados dos sistemas de informação tem sido considerada importante para todas as áreas e categorias do setor saúde. Isso tem gerado ações visando a aperfeiçoar a qualidade dos dados. Entre essas, propõe-se que a categoria considere a situação em que se encontram os registros dos procedimentos, porque estes são a base para os cálculos de pagamento das ações especializadas, como também são meios para o planejamento e avaliação dos serviços prestados;

A análise dos dados disponíveis pode subsidiar formulações que reafirmem ou renovem as políticas de saúde. Faz-se necessário que, no exercício profissional, os psicólogos incorporem o repensar dessas políticas. Esse é um desafio à identidade profissional que deve conceber o psicólogo como um trabalhador da saúde, capaz de contribuir para a formulação e a implantação dessas novas políticas;
- Responder às demandas da saúde mental não é uma ação "menor",o desafio da reforma psiquiátrica, o incremento da desospitalização e a humanização das práticas em saúde que contemplem os portadores de sofrimento psíquico devem contar com a ação de psicólogos nos diversos contextos e níveis de atenção;

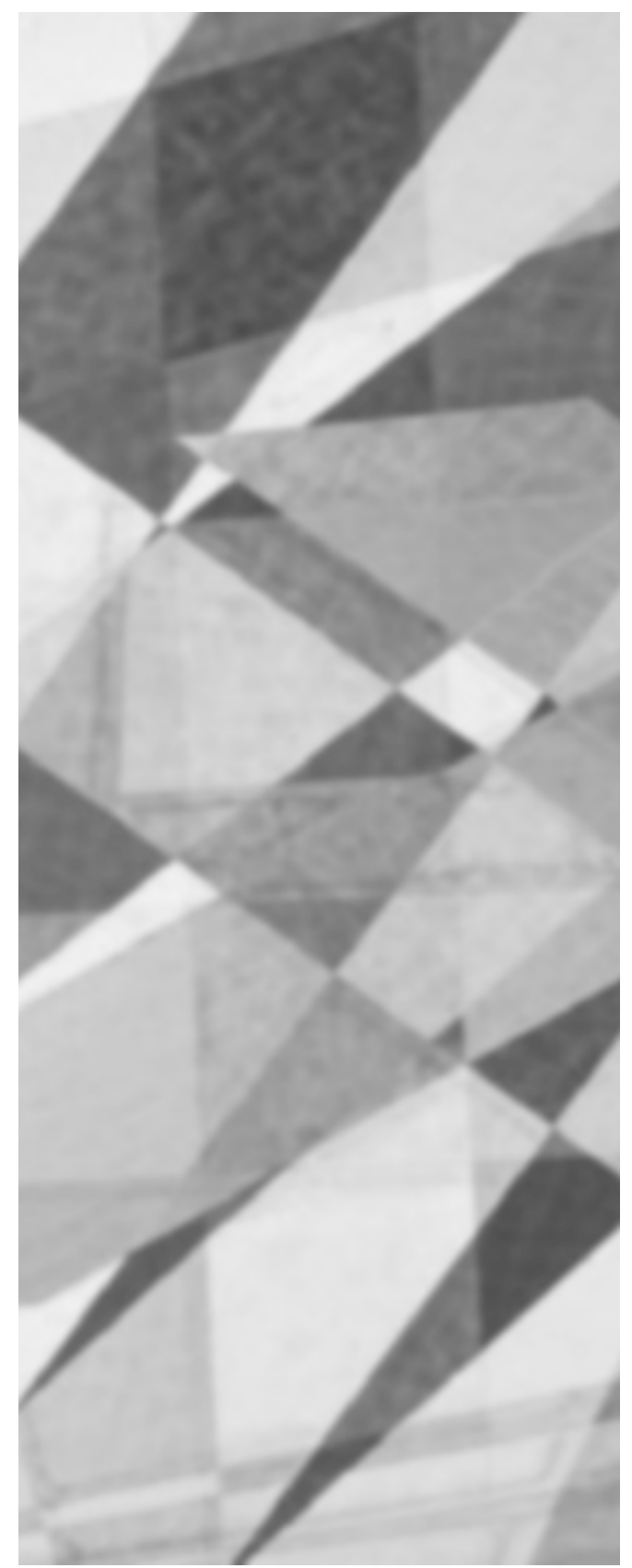

"Não se pode perder de vista que a incorporação de novos profissionais ou a oferta de ações do psicólogo em saúde pública se defronta com uma realidade na qual se observa a flexibilização das profissõese o enxugamento dos quadros do Estado"

Yamamoto

- A construção permanente de bases teóricas e, conseqüentemente, o repensar das estratégias de ação promoverão a ampliação da ação do psicólogo, tanto no que diz respeito aos níveis de atenção quanto aos contextos de atendimento. 
Parece que, historicamente, nós nos recusamos a trabalhar em serviços de urgência e emergência não teria sido essa concepção de atuação orientada por uma demanda, demanda submetida a um enquadre específico, geradora do fortalecimento das práticas de medicalização?
Este texto pretende, ao mesmo tempo, trazer informações para subsidiar reflexões relacionadas à condição da profissão e da categoria e gerar o debate conseqüente. É muito importante que se realizem outras análises sobre estes e outros dados semelhantes.
Parece que, historicamente, nós nos recusamos a trabalhar em serviços de urgência $\Theta$ emergência - não teria sido essa concepção de atuação orientada por uma demanda, demanda submetida a um enquadre específico, geradora do fortalecimento das práticas de medicalização?

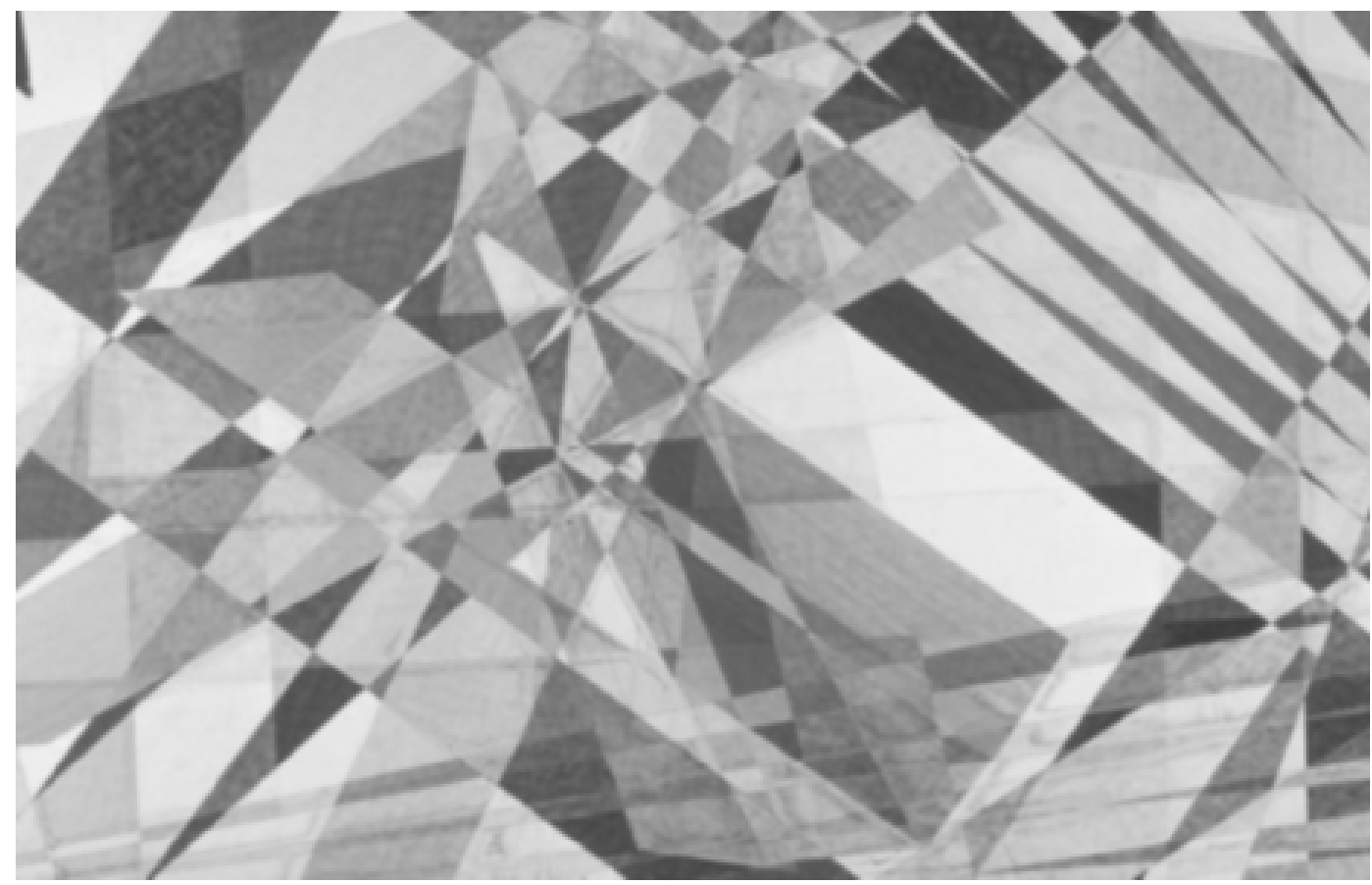


Anamélia Franco \& Eduardo Mota Universidade Federal da Bahia - Instituto de Saúde Coletiva R. Padre Feijó, 29, 4 andar, Canela 40.110-170, Salvador, Bahia Tel.: (71)245 0544; fax (71)2375856 E-mails:anamelia@ufba.br;emota@ufba.br

BOCK, A.M.B. Eu Caçador de Mim. In: OConhecimento no Cotidiano. São Paulo: Brasiliense, 1998,p.280-291.

CONSELHO FEDERAL DE PSICOLOGIA. Quem éo Psicólogo Brasileiro? São Paulo: EDICON, 1988.

MINISTÉRIO DASAÚDE. Norma Operacional Básica do Sistema Único de Saúde/NOB-SUS 01/96. Brasil, Minisitério da Saúde, 1997.

SIIVA, R.C. A Formação em Psicologia para o Trabalho em Saúde Pública. In: Campos, F.C.B. Psicologia e Saúde. Repensando práticas. São Paulo: Editora HUCITEC, 1992, p.25-40.
SPINK, M.J. Psicologia da Saúde: a Estruturação de um Novo Campo de Saber. IN Campos, F.C.B., Psicologia e Saúde. Repensando Práticas. São Paulo: Editora HUCITEC, 1992

YAMAMOTO, O. H. Neoliberalismo e Políticas Sociais: o Impacto na Psicologia Brasileira. Psicologia Revista, 2, 1996, pp. 13-26. 